\title{
Práticas Disciplinares e Usos de Drogas: A Gestão dos Ilegalismos na Cena Contemporânea
}

Disciplinary practices and drug use: Ilegalism management in contemporaneous scene

Waleska

Borges Cheibub

Centro de Atenção

Psicossocial - Álcool e

Drogas Alameda

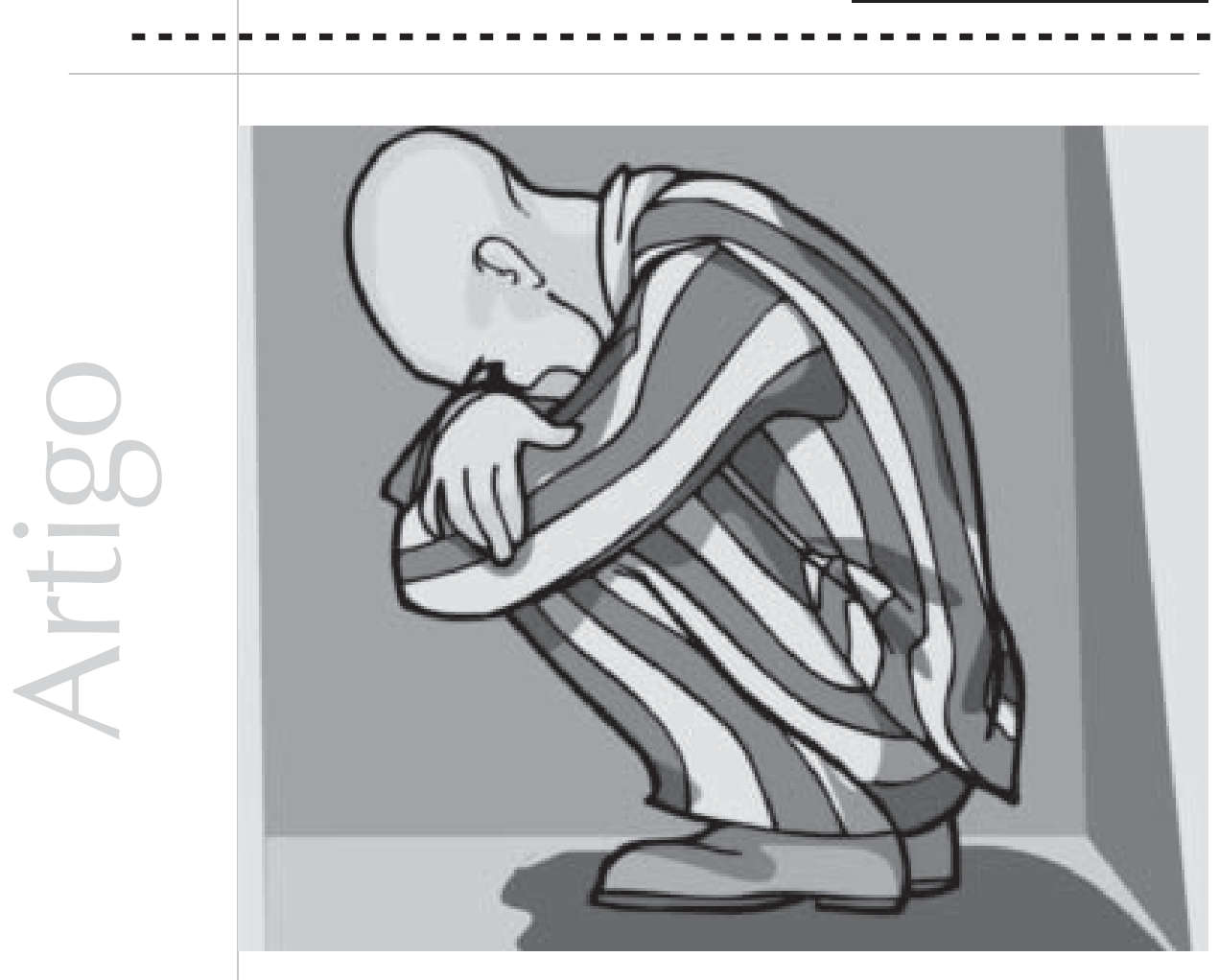




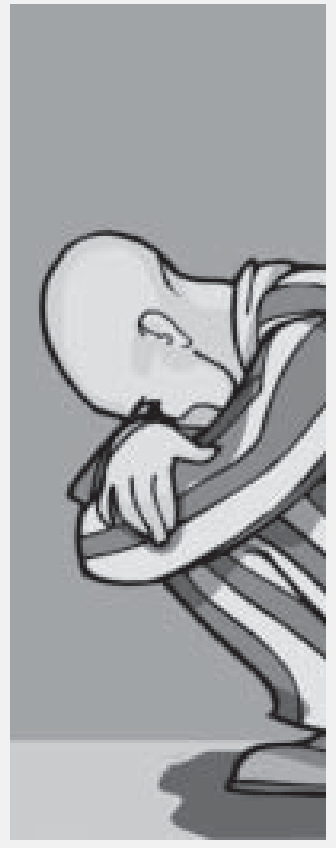

Resumo: O presente artigo pretende abordar a problemática da droga em sua relação com o sistema prisional. Partindo dos pressupostos postulados por Michael Foucault, afirmamos que o poder de punir diz respeito menos à mera repressão relativa ao uso de substâncias psicoativas do que à gestão dos ilegalismos. As relações de poder e saber, implicadas no conjunto das técnicas disciplinares, estão diretamente relacionadas com a norma e sua conseqüente produção de verdades.

Palavras - chave: droga, ilegalismo, disciplina e norma.

Abstract:This article focuses the issue of drug use and its relation to the prisional system. According to Michel Foucault, the power to punish is less likely to function as a mere repressive act towards the use of psychoactive substances. Its real purpose can be more accurately referred to the management of ilegalisms. The relations between power and knowledge - found within the disciplinary techniques - are related to the norm and to the production of truth.

Key - words: drug, ilegalism, discipline, norm.

Tomamos como objeto de estudo a problemática da droga em sua relação com o sistema prisional tal como postulado por Foucault.

De acordo com Foucault, é necessário deslocar a idéia de que o sistema punitivo tem, como função primária, simplesmente sancionar, para a concepção de que os mecanismos punitivos produzem efeitos de subjetividades.

É nesse sentido que o autor traz à cena o sistema punitivo moderno em seu correlato mais imediato: a prisão. A prisão é originária de uma tecnologia política do corpo, ou seja, de uma forma de organização política em que a penalidade se transforma menos num controle incidindo sobre a infração à lei do que numa gerência acerca do que os indivíduos são capazes de fazer.

Isso implica dizer que a exclusão propiciada pela prisão é, na verdade, uma inclusão. Além de moldar os corpos dos indivíduos através de uma arquitetura de controle social, tal inclusão permite que eles se mantenham num determinado campo de normas (Foucault, 1996).
Hoje, podemos pensar que um novo personagem - o "drogado" - toma a cena, tornando-se um dos principais elementos de legitimação do sistema penal e de seus correlatos, como a prisão e a polícia. Nesse caso, o poder de punir diz menos respeito à mera repressão em relação ao uso de substâncias psicoativas do que à gestão dos ilegalismos.

\section{Regras de Direito, norma e produção de verdade: aliança entre Justiça e terapêuticas}

No documento Desenvolvimento e Implementação de Sistemas de Tribunais para Dependentes Químicos (1999), o tribunal de drogas é apresentado como o mais eficaz modo de controle não só do uso de substâncias químicas mas também da criminalidade em geral e de crimes relacionados ao uso de substâncias. Esse é o argumento dado à implementação de um sistema de tribunais que alcança toda a população de consumidores de substâncias psicoativas nos EUA (cf. National Drug Court Institute, 1999, p. 8).
- Bem - disse eu, tocando o braço - o dever me chama. Como um juiz dizia ao outro: Sê justo e, se não puderes ser justo, sê arbitrário.

William S. Burroughs 
Quais são as regras de direito de que lançam mão as relações de poder para produzir discursos de verdade?
O programa estabelece uma combinação de supervisão judicial intensa, testes compulsórios para controle de uso de drogas, penalidades cada vez mais severas e finaliza com um tratamento que visa a causar uma ruptura com o chamado "ciclo do vício" e, e conseqüência, com o crime a ele associado.

Outro documento, chamado de Definindo os Tribunais para Dependentes Químicos: os Componentes Chave (1997), toma como pressuposto o fato de o tratamento começar na sala de audiências, sendo que o tribunal deve se constituir, então, um amplo campo terapêutico, garantindo, não só aos profissionais que integram a equipe de tratamento mas também aos profissionais da justiça criminal, o cunho de serem uma equipe terapêutica (cf. Divisão de Programas de Tribunais para Dependentes Químicos, 1997, P. 25).

No Brasil, como se verifica pela tradição de importação de modelos norte-americanos, temos um programa similar para dependentes que é cunhado de Justiça Terapêutica.

A implantação dos tribunais de drogas, nos EUA, segue determinada política que prevê, na verdade, "mais tratamento, sob a ameaça de cárcere" (Maierovitch, 2002, p.5).

Mas, seguindo o referencial teórico desenvolvido por Foucault, dizer que esse tipo de programa tem, por si só, uma existência coercitiva ou repressiva é empobrecer a rede de relações que permeiam a história do uso de substâncias psicoativas.

Seria muita ingenuidade acreditar que o conjunto de postulados que compõem esses projetos é neutro, pois observa-se que a questão dita "repressiva" envolvida nas questões do uso de substâncias psicoativas não pertence a um conjunto de regras de direito pura e simplesmente, mas a um conjunto de técnicas disciplinares cujas relações de poder e saber estão diretamente implicadas com a norma e com a sua conseqüente produção de verdades.
A partir de determinado momento de sua obra, Foucault percorre os mecanismos de poder através de dois pontos de referência: por um lado, as regras de direito que incidem formalmente no poder, e, por outro lado, os efeitos de verdade produzidos pelo poder. Esses dois limites conduzem ao que ele chama de triângulo entre poder, direito e verdade (cf. Foucault, 1999, p. 28).

A interrogação básica a que esse tipo de pesquisa conduz seria, nas palavras de Foucault:

Quais são as regras de direito de que lançam mão as relações de poder para produzir discursos de verdade? Ou ainda: qual é esse tipo de poder capaz de produzir discursos de verdade que são, numa sociedade como a nossa, dotados de efeitos tão potentes? (ibid., p. 28).

Com isso, se múltiplas relações de poder atravessam o corpo social, elas não podem se legitimar sem uma produção de um discurso verdadeiro que vão além das regras de direito, pois "afinal de contas", escreve Foucault, "somos julgados, condenados, classificados, obrigados a tarefas, destinados a uma certa maneira de viver ou a uma certa maneira de morrer em função de discursos verdadeiros, que trazem consigo efeitos específicos de poder" (ibid., p. 29).

Na cena contemporânea, é verificado um incremento da produção de discursos sobre as drogas. A conjugação de discursos advindos de uma série de instituições como a Medicina, a Justiça, a polícia e a imprensa, entre outras, serve à produção de verdades que conduzem à homogeneidade das discussões.

Então, se os programas de tribunais prevêem a produção de verdades sobre os indivíduos baseados em perfis, esse saber produzido será utilizado pelas regras de direito a fim de oferecer a melhor e mais adequada punição (aquela que melhor controlará corpos e almas). 
Considerando tais efeitos de produção de verdades em relação ao uso de substâncias psicoativas, uma afirmação equivocada seria a de que as práticas jurídicas fixam a produção da categoria de criminoso/delinqüente, por um lado, e, por outro, a prática médica estabelece a doença e o vício. Essa separação velaria a própria prática que conduz à indistinção entre viciado e criminoso.

Por isso, não se trata de escolher se a problemática do uso de drogas pertence ao campo da Justiça ou da Medicina, uma vez que essa questão só é pertinente a partir da própria junção entre essas duas instâncias. Assim, a Justiça penal acrescenta, ao delito, (portar drogas) tanto a categoria de delinqüência quanto a de drogadicção e de doença. A punição ganha ares de regeneração dos usuários de drogas, sendo punição e cura termos indissociáveis nessa prática.

A fabricação de um tal campo de verdades garante ao castigo seu poder máximo, ou seja, o de fixar-se como terapêutica e discurso de saber ao mesmo tempo. Naturalmente, é necessário, aos juízes, "medir, avaliar, diagnosticar, reconhecer o normal e o anormal e a honra reivindicada de curar ou readaptar" (Foucault, 1991, p. 265).

Se tais programas de tribunais de drogas nada mais são do que um mecanismo disciplinar cuja função é regular os desviantes de acordo com a norma, acompanhamos Buscher (1993) quando ele diz que a questão da drogas tem, como ação mais potente, o "papel de disciplinarização das pessoas, na medida em que compactua com normas de conduta constitutivas de um amplo projeto normalizador das relações sociais" (Buscher, 1993, p. 39).

\section{Drogas: a gestão dos ilegalismos na cena contemporânea}

Se a manutenção da prisão está no cerne da penalidade moderna e esta tem como função a gestão das ilegalidades mediante sua distinção, distribuição e utilização, o sistema de punições não visa a extinguir ou a reprimir a infração, e sim,

(...) riscar limites de tolerância, de dar terreno a alguns, de fazer pressão sobre outros, de excluir uma parte, de tornar útil outra, de neutralizar estes, de tirar proveito daqueles. Em resumo, a penalidade não 'reprimiria' pura e simplesmente as ilegalidades; ela os 'diferenciaria', faria sua 'economia' geral. E, se podemos falar de uma Justiça, não é só porque a própria lei ou a maneira de aplicá-la servem aos interesses de uma classe, é porque toda a gestão diferencial das ilegalidades por intermédio da penalidade faz parte desses mecanismos de dominação. Os castigos legais devem ser recolocados numa estratégia global das ilegalidades (Foucault, 1991, p. 240).

Tal gestão diferencial de que nos fala Foucault contribui para uma generalização de discursos que, por definirem a classe social, geram o medo. A partir da miséria e dos vícios que formam o criminoso, conclui-se que "nos tribunais, não é a sociedade inteira que julga um de seus membros, mas uma categoria social encarregada da ordem sanciona outra fadada à desordem" (ibid., p. 243).

De acordo com isso, a prisão tem o seu objetivo bem consolidado ao especificar a delinqüência, que não é senão uma "forma política ou economicamente menos perigosa - talvez até utilizável - de ilegalidade, de produzir os delinqüentes, meio aparentemente marginalizado, mas centralmente controlado, de produzir o delinqüente como sujeito patologizado" (ibid., p. 244). ${ }^{1}$

Essa gerência concede à delinqüência a definição de ser um agente para as práticas ilegais dos grupos dominantes. Foucault lança um exemplo que particularmente nos interessa:
(...) riscar limites de tolerância, de dar terreno a alguns, de fazer pressão sobre outros, de excluir uma parte, de tornar útil outra, de neutralizar estes, de tirar proveito daqueles. Em resumo, a penalidade não 'reprimiria' pura e simplesmente as ilegalidades; ela os 'diferenciaria', faria sua 'economia' geral.

Foucault
1 Isso é importante pois, ao contrário da afirmação corrente de que a prisão produziria delinqüência por não corrigir suficientemente os indivíduos, tem-se a circunscrição da delinqüencia como efeito de uma gestão das ilegalidades. 
os tráficos de armas, os de álcool, nos países de lei seca, ou, mais recentemente, os de drogas, mostrariam, da mesma maneira, esse funcionamento da 'delinqüência útil'; a existência de uma proibição legal cria, em torno dela, um campo de práticas ilegais, sobre o qual se chega a exercer controle e a tirar um lucro ilícito por meio de elementos ilegais, mas tornados manejáveis por sua organização em delinqüência; esta é um instrumento para gerir e explorar as ilegalidades (ibid., p. 246).

Dessa forma, a guerra às drogas do governo norte-americano é designada como uma política que se dirige prioritariamente aos vendedores de rua pertencentes à população pobre dos guetos, o que promove nada mais, nada menos que um crescimento vertiginoso da população carcerária nos Estados Unidos (cf. Wacquant, 2001, pp. 29-31). ${ }^{2}$

Tal crescimento do Estado penal se referiria menos à ascensão da criminalidade do que a uma precarização do Estado-previdência. A droga, a violência, a desagregação familiar e social do gueto, entre outros, se tornam mira do Estado (cf. Wacquant, 2001, p. 32).

O recurso à prisão, com a conseqüente quadruplicação da população encarcerada em vinte anos, é explicada por se dirigir a crimes e delitos como os estupefacientes e atentados à ordem pública, ou seja, a punição visa aos delinqüentes de Direito comum. Esse aumento indica menos o aumento da criminalidade e mais o aumento de uma "varredura" em relação aos futuros delinqüentes. As 'desordens' cotidianas, nas famílias pobres, passam a chamar a atenção de modo a que o Estado penal reafirme o trabalho e a moralidade como forma de controle (cf. ibid., pp. 62-64). ${ }^{3}$

Se Foucault revela, em seu estudo, que a prisão fornece a readaptação de uma força de trabalho mal utilizada como instrumento a ser utilizado como possível reserva, Wacquant
(2001) nos propõe que, atualmente, ela é uma forma de encarceramento do refugo do mercado de trabalho (cf. ibid., p. 140).

Não obstante essa característica, o autor segue Foucault e foge das análises simplistas da política econômica neoliberalista, que consideram a função da prisão como excludente e repressiva. Ao contrário, a função primária do instrumento prisional é produzir novas realidades, tais como a noção de populações perigosas, de violências urbanas e do slogan tolerância zero, assim como de discursos sobre a segurança geradora de tutelas policiais e penais das classes populares e de instituições e de dispositivos jurídicos para contenção dos desvios (cf. ibid., pp.140-141). Se a criminalidade é um álibi para o fortalecimento do controle da sociedade, há sempre um grupo à margem: as classes perigosas. Segundo Foucault (1971a-2003), "existe a população das favelas, a dos subúrbios superpopulados, os imigrados e todos os marginais, jovens e adultos. Nada surpreendente se os encontramos, sobretudo eles, diante dos tribunais de Justiça ou atrás das grades" (Foucault, 1971a -2003, p. 12). A droga é mais um veículo, quiçá um dos principais atualmente, para o exercício de gestão de controle através do sistema carcerário e de todos os dispositivos nele incluídos.

Foucault (1975b-2003) destaca que, nos EUA, existem quatro caminhos que conduzem à prisão, a saber, a droga, a prostituição, o jogo e os cheques. Como explicação disso, Foucault realmente não escolhe o caminho mais fácil, que seria o de achar que essas seriam delinqüências de ruptura, mas ele baseia seus argumentos naquilo que precisa ser conservado e naquilo que serve à lei para o seu exercício:

Delinqüência de ruptura? Não. Mas derivação mais ou menos rápida a partir do tolerado, do meio-legal, do parcialmente ilícito, ramificação sobre um tráfico aceito, protegido, integrado a todas as atividades 'honestas', e das quais 
os prisioneiros são, a um só tempo, a mãode-obra febril, os subempreiteiros ardilosos e cegos, as mais fáceis vítimas. Diz-se facilmente - seja para 'psiquiatrizá-los', seja para 'heroizálos' - que eles são 'marginais'. Mas as margens onde circulam não são marcadas pela fronteira da exclusão; elas são os espaços discretos e ensurdecidos que permitem ao perfil mais honroso se estender e à lei mais austera se aplicar. O que um certo lirismo chama de 'margem' da sociedade, e que se imagina como um 'fora', são os intervalos internos, as pequenas distribuições intersticiais que permitem o funcionamento (Foucault, 1975b2003, p. 147).

Então, podemos dizer que os objetivos da guerra às substâncias psicoativas fracassam não somente pelo fato de a revenda da cocaína não cair, mas pela quantidade de droga em circulação que cresceu e pelo número de pessoas presas que aumentou. É preciso questionar, junto com Wacquant, se essa não seria uma missão não confessada por essa política (cf. Wacquant, 2001, p. 30).

Está provado que a escassez da droga não inibe o consumo, apenas leva à elevação do preço do produto, justamente pela regulação econômica do valor da droga a ser dada pela repressão.

Isso já foi constatado em 1930, nos EUA, quando houve aumento artificial do preço de bebidas alcoólicas após a proibição, com a Lei Seca. Além disso, aparece a circulação de outras drogas, como ocorreu após a década de 1970, nos EUA, em que houve crescimento da oferta de cocaína e heroína pela repressão dada à maconha e aos alucinógenos de origem mexicana (cf. Karam, 2001, p. 535). Por sua vez, se foi anunciado no governo Reagan um declínio de $10 \%$ no uso de crack, não é noticiado que, nessa mesma época, houve um acréscimo do consumo de cocaína e heroína (cf. Costa, 1997, p. 197).
Por isso, a criminalização e a estrutura de mercado caminham juntos, uma vez que a produção e a comercialização de produtos ilícitos é incentivada, cada vez mais, pelos lucros gerados pela elevação dos preços (cf. Karam, 2001, p. 535).

Temos aqui, então, dois pontos interligados na gestão dos ilegalismos atualmente. De um lado, o "interesse" penal em relação à chamada classe perigosa ou classe à margem, que, como vimos, pertence intimamente à própria extensão de um tráfico aceito, banalizado, e no qual "a lei" não precisa interferir; de outro lado, a própria estrutura penal e carcerária, que permite à estrutura de mercado montar suas estratégias de ganhos e lucros.

\section{A experiência brasileira}

Retornando às colocações de Wacquant (2001), Batista (2002) afirma que o ideal de pureza da pós-modernidade se insere na criminalização das questões sociais. Essa perspectiva corrobora, não sem motivo, o fato de a política criminal de drogas se dirigir aos pobres em todos os países.

Em pesquisa realizada nos processos dos juizados de menores no período de 1968 a 1998, Batista (1998) verifica como o sistema penal brasileiro é bipartido em pobres e ricos. Aos ricos, aplica-se o paradigma médico, e, aos pobres, o paradigma penal.

A autora afirma que o cerne da questão se encontra no controle específico da juventude pobre considerada perigosa, e não no da droga em si. Dessa forma, nas falas colhidas nos processos, elas "se relacionam às famílias 'desestruturadas', às 'atitudes suspeitas', ao 'meio ambiente pernicioso, à sua formação moral', à 'ociosidade', à 'falta de submissão', ao 'brilho no olhar' e ao desejo de status 'que não se coaduna com a vida de salário mínimo'" (ibid., p. 123). 
Um dos fatores apontados por Batista (2002) a fim de justificar esse sistema penal de extermínio é a produção de um discurso moral sobre o crime (cf. Batista, 2002, p.207).

A mídia não se esquiva a essas distinções. Temos visto o quanto a imprensa valoriza a repartição entre favela e asfalto, e conseqüentes adjetivos como mal e bem, sujeira e limpeza. Assim, metáforas da culpa e da recriminação social ricocheteiam na estrutura social e diversos setores vulneráveis passam a ser demonizados. A mídia surpreende pelas notícias do atípico, do que pode perturbar a 'normalidade'(motoboys, chupacabras, pedófilos). Para o pânico moral, surgem tratamentos e panacéias que variam das castrações químicas às chacinas sangrentas (ibid.p. 211).

A imprensa, ultimamente, tem dado ampla cobertura aos crimes relacionados ao uso de drogas, principalmente nos crimes de âmbito doméstico.

A reportagem realizada pelo jornal O Globo apresenta um crime cujo enfoque privilegia o uso de substâncias psicoativas. A notícia relata como um pai matou o próprio filho através da destrutividade causada pelo uso de drogas. A reportagem é iniciada com o seguinte juízo: “mudam os personagens, mas histórias de famílias destruídas pelas drogas se repetem. Começam com o filho dominado pelo vício e acabam em violência" (Brandão, 19/04/03, p. 9) ou ainda, "a capacidade de devastação que a dependência química pode produzir numa família" (ibid.).

Esses e outros casos comumente alardeados nos informam que o delito é transformado em delinqüência assim que se produz, pela mídia, a "informação" de uma série de crimes cuja função é somente atestar a periculosidade dos envolvidos, ou melhor, atestar a periculosidade da droga. A série mídia-família
- droga - polícia - Justiça legitima a delinqüência e justifica o poder de punir do Estado penal, pois, afinal, não há "todos os dias, nos jornais, artigos onde se conta o quão numerosos e perigosos são os delinqüentes?" (Foucault, 1979, p. 138).

Souza (1993) afirma que a mídia, sob o domínio do registro, não consegue escapar de atribuir qualidades aos indivíduos com o objetivo de classificá-los (Souza, 1993, p. 279). Com efeito, em Vigiar e Punir (1991), Foucault nos mostra como foram produzidas, em torno dos delinqüentes, definições bem marcadas, cuja função é torná-los difundidos pelo corpo social, próximos e temíveis. O noticiário policial atesta sua função "por sua redundância cotidiana, torna aceitável o conjunto dos controles judiciários e policiais que vigiam a sociedade; conta, dia a dia, uma espécie de batalha interna contra o inimigo a ser visto; nessa guerra, constitui o boletim cotidiano de alarme ou de vitória" (Foucault, 1991, p. 251). Se a mídia se inclui no sistema panóptico da sociedade disciplinar, não é sem razão que há uma "subordinação do discurso político às agências de comunicação" (Batista, 2001, p. 8), ou seja, através da mídia, o discurso político exerce, de forma mais justificada e embasada, seu poder de punir.

Os artigos publicados pela mídia manipulam o "pânico" produzido pelos crimes relacionados ao uso de drogas até suscitar o pedido de uma intervenção do Estado, a partir de uma ingerência encontrada no "seio familiar" em geral. Esse chamado discurso do medo propõe ser a droga uma nova peste ou epidemia que precisa ser controlada.

Batista (2002) sugere uma análise voltada para o fato de o medo se tornar um modo de interpretação da realidade ao justificar políticas autoritárias de controle social destinadas às classes empobrecidas.

Se há crise social ou econômica, faz-se apelo a um governo policial em nome da ordem 
pública. Funcionando como um nacionalismo interno, o medo cria o pedido de poder policial (cf. Foucault, 1975a-2003, p. 157).

É nesse sentido que o controle policial, cúmplice do panóptico, promove a fiscalização do corpo social. O tríplice sistema prisãopolícia-delinqüência sustenta a criminalidade como uma engrenagem do poder. Foucault nos contempla com uma importante afirmação:

O teatro polícia-delinqüência, que ocupa um lugar tão amplo em tudo o que se lê e se vê desde o século XIX, é um dos complementos e dos contrapesos indispensáveis do sufrágio universal. Para que a lei possa valer comodamente em sua existência secreta, para que a ordem possa impor coações, é preciso que haja, não nas fronteiras exteriores, mas no próprio centro do sistema, e como uma espécie de jogo para todas as suas engrenagens, essas zonas de 'perigo' que são silenciosamente toleradas, e depois magnificadas pela imprensa, pela literatura policial, pelo cinema. E pouco importa, finalmente, que o criminoso, ali, seja apresentado como um herói da revolta pura, ou como um monstro humano apenas saído das florestas, contanto que ele faça medo (Foucault, 1975b-2003, p. 148).

Essa sustentação da criminalidade mantém o Estado penal como saída à falência de políticas públicas que contemplem as classes menos favorecidas. Se o Estado neoliberal amplia o controle social através do poder de punir, ele pede uma vigilância máxima, panóptica, que, cada vez mais, acarreta a criação de novos dispositivos que restringem o direito individual. Karam (1998) destaca que trazer o foco do problema para a criminalidade e sua conseqüente "repressão e castigo" mantém a coesão social e o silêncio sobre a desestruturação econômico-social. Na criação de novos inimigos e fantasmas, não se discute a carência de concepções retributivistas das políticas públicas. A solução oferecida é a entrada em cena do universo carcerário, sendo o "tema das drogas que mais fortemente hoje atua a enganosa publicidade que consegue 'vender' o sistema penal como o produto destinado a fornecer as almejadas proteção, tranqüilidade e segurança" (Karam, 1998, p. 251).

Com a difusão da pretensa eficácia do sistema penal, o que vemos é uma população aprisionada na contenção de uma criminalidade produzida pelo amplo sistema de vigilância. De acordo com Foucault:

Nenhum de nós pode ter certeza de escapar à prisão. Hoje, menos do que nunca. Sobre nossa vida do dia a dia, o enquadramento policial estreita o cerco: nas ruas e nas estradas, em torno dos estrangeiros e dos jovens. $\mathrm{O}$ delito de opinião reapareceu: as medidas antidrogas multiplicam a arbitrariedade. Estamos sob o signo do 'vigiar de perto'. Dizem-nos que a Justiça está sobrecarregada. Nós bem o vemos. Mas, e se foi a polícia que a sobrecarregou? Dizem-nos que as prisões estão superpovoadas. Mas, e se foi a população que foi superaprisionada? (Foucault, 1971b - 2003, p. 2).

Vejamos o que o próprio Bentham (Bentham, 1787-2000), idealizador da arquitetura panóptica, nos diz sobre esse modelo:

Se você visse a moral reformada, a saúde preservada, a indústria revigorada, a instrução difundida, os encargos públicos aliviados, a economia assentada, como deve ser, sobre uma rocha, o nó górdio das leis sobre os pobres não cortado, mas desfeito - tudo por uma simples idéia de arquitetura? (Bentham, 1787-2000, p. 72).

É mantendo esse ponto de vista que afirmamos, junto com Baratta (1998), que "a droga não é mais que a última ocasião com a qual o sistema punitivo da sociedade moderna
O teatro políciadelinqüência, que ocupa um lugar tão amplo em tudo o que se lê e se vê desde o século XIX, é um dos complementos e dos contrapesos indispensóveis do sufrágio universal. Para que a lei possa valer comodamente em sua existência secreta, para que a ordem possa impor coações, é preciso que haja, não nas fronteiras exteriores, mas no próprio centro do sistema, e como uma espécie de jogo para todas as suas engrenagens, essas zonas de 'perigo' que são silenciosamente toleradas, e depois magnificadas pela imprensa, pela literatura policial, pelo cinema.

Foucault

4Além dos Estados Unidos, conforme já visto, o inegável aumento dos processos judiciais é observado até em países considerados liberais, como a Holanda e a Noruega. No Brasil, - Censo de 1995. realizado pelo Conselho Nacional de Politica Criminal e Penitenciária do Ministério da Justiça, mostra que as conden açóes relacionadas a drogas ilicitas ocupam a quarta posição entre as pessoas punidas com penas privativas de liberdade (Karam, 2001, p.531) 
realiza a sua história, que é a mesma no Brasil e no resto do mundo" (Baratta, 1998, p. 15). Isso nos conduz a dizer, junto a Ewald (2000), que "a tarefa primeira do poder é positiva: produzir. Só depois, e por conseqüência, é que será necessário reprimir, mas sempre em vista de efeitos úteis e positivos, o que Foucault chama de gerir" (Ewald, 2000, p. 44). A penalidade, seja sob a forma "abrandada", seja a própria prisão, nada mais é do que uma forma de defesa da sociedade em virtude do dano social. No caso do mais novo personagem da cena contemporânea, o drogado, verificamos que a penalidade é dada como a resposta mais imediata.

Essa penalidade é infringida ao corpo social como dano causado à estrutura familiar até à concepção de dano causado à estrutura social como um todo, a partir da correlação feita entre periculosidade e drogas. Estão aí para atestar tal conjuntura os programas de Drug Courts norte-americano e seu similar brasileiro, a Justiça terapêutica, que nada mais são do que práticas disciplinares que têm como princípio gerir os drogados como a mais recente versão da delinqüência.

\section{Conclusão}

De acordo com Foucault, se a lei é colonizada pelas disciplinas, tornando-se, dessa maneira, tanto um aparato normalizado quanto normalizador, no caso do uso de drogas, esse funcionamento não ocorre de forma diferente. Para a lei, não basta que tal uso seja considerado um delito, sendo-Ihe acrescentada uma série de outras categorias, tais como viciado, doente e criminoso, legitimando, assim, a necessidade de penalidade e/ou de tratamento.

Isso torna possível a verificação de outra vertente nesses programas de tribunais de drogas. Se o sistema carcerário pressupõe uma nova forma de lei - a norma -, ao juiz não cabe mais somente a punição, mas a cura e a readaptação, intensificando, assim, o poder de punir. Na aliança entre terapêutica e
Justiça, o objeto a sofrer os efeitos da normalização é o delinqüente-drogado, o que conduz à indistinção viciado-criminoso. A confluência infrator-sujeito readaptado permite a sua objetivação, para então regular os desviantes da norma.Tal objetivação é autenticada por verdades que conduzem à concepção de que a droga é associada à capacidade de corrupção da moral, à violência, à destruição do próprio corpo e das relações familiares, entre outros desvios e desordens psicológicas associadas à prática de crimes.

Essas verdades nos levam de volta à íntima correlação entre vício e infração. Com tantos atributos, ela permite que haja o reconhecimento do perigo que o indivíduo em questão representa para a sociedade.

Dessa forma, em relação à droga, deve-se levar em conta não a repressão, meramente, mas os mecanismos muito mais eficazes e insidiosos. Mediante a distinção entre o que é legal e o que é ilegal, são lançadas outras categorias que ultrapassam essa distinção. Ao atestar a periculosidade da droga em um verdadeiro processo de demonização, a série mídia - família - droga - polícia - justiça legitimam-na como um dos principais elementos de justificativa do Estado penal, ordenando maior marginalização como melhor forma de controle. A seqüência Direito penal, crime, atuação policial e ação penal demonstram, nada mais, nada menos, que é a droga, enquanto criminalidade, que é o objeto de intervenção penal.

O usuário de drogas, enquanto criminoso, delinqüente, viciado ou outro termo qualquer, pressupõe tanto o isolamento quanto a conseqüente inclusão desse personagem. $\mathrm{O}$ processo de objetificação é verificado, o que rotula o drogado como criminoso e, por isso, sujeito a estar fora do pacto social, o que o conduz de volta a categorias como a de delinqüente, no manejo do sistema classificatório e punitivo.

Isso nos permite apontá-lo como o mais novo estrangeiro da contemporaneidade, mas, como 
Freud já dizia, o estrangeiro ou o estranho pertence intimamente ao que há de mais familiar. Com a droga, não é diferente, uma vez que ela indica o que há de mais estrangeiro e o que há de mais íntimo em nossa estrutura social: o próprio sistema penal.

Assim, a prisão tem sua visibilidade marcada por ser um lugar de exclusão que se reinscreve no corpo social, na medida em que "ela se torna sua localização mais luminosa, a mais próxima, a mais familiar" (Miller, 2000, p. 83). A arquitetura panóptica e todos os aparatos disciplinares discutidos neste trabalho se encarregam dessa reinscrição, pois, como disse Victor Hugo (1995), "Nada de carrasco onde basta o carcereiro" (Hugo, 1995, p. 25).

\section{Waleska Borges Cheibub}

Psicóloga lotada no Centro de Atenção Psicossocial para Usuários de Àlcool e outras Drogas - CAPS AD Alameda - Niterói. Graduação pela UFRJ em dezembro de 1998. Curso de Especialização em Teoria Psicanalítica pelo Instituto Brasileiro de Medicina e Reabilitação (IBMR).

Curso de Especialização para a Rede dos Centros de Atenção Psicossocial no Atendimento a Dependentes de Álcool e outras Drogas pelo Instituto de Psiquiatria da UFRJ, em parceria com o Ministério da Saúde (IPUB/UFRJ/MS). Rua Paulino Fernandes, 25, ap. 104 - Botafogo - Rio de Janeiro - RJ - CEP 22270-050; Tel: (21) 22262022 ou (21) 91797762; E-mail:cheibub@ig.com.br

Recebido 14/12/05 Reformulado 17/10/06 Aprovado 09/11/06

BARATTA, A. Prefácio. In: Batista, V. M. Difíceis Ganhos Fáceis. Drogas e Juventude Pobre no Rio de Janeiro. Rio de Janeiro: Instituto Carioca de Criminologia - Freitas Bastos Ed., 1998.

BATISTA, V. M. Difíceis Ganhos Fáceis. Drogas e Juventude Pobre no Rio de Janeiro. Rio de Janeiro: Instituto Carioca de CriminologiaFreitas Bastos Ed., 1998.

Prefácio. In: Wacquant, L. Punir os Pobres: a Nova Gestão da Miséria nos Estados Unidos. Rio de Janeiro: Instituto Carioca de Criminologia - Freitas Bastos, 2001.

Medo na Cidade. In: Plastino, C. A. (org.) Transgressões. Rio de Janeiro: ContraCapa Livraria, 2002.

BENTHAM, J. O Panóptico ou a Casa de Inspeção (1787). In: Silva, T. T. da (org.). O Panóptico. Jeremy Bentham. Belo Horizonte: Autêntica 2000.

BRANDÃO, T. Famílias Destruídas pelas Drogas. OGlobo, Rio de Janeiro, 19/04/03, Rio, p.9.

BUCHER, R. As Drogas e as Ideologias da Prevenção. In: Drogas: uma Visão Contemporânea. Rio de Janeiro: Imago Ed., 1993.

COSTA, N. F. DA. Subsídios para a Discussão da Política das Toxicodependências. In: Batista, M. \& Inem, C. Toxicomanias: uma Abordagem Multidisciplinar. Rio de Janeiro: NEPAD/UERJ - Sette Letras, 1997

DIVISÃO DE PROGRAMAS DE TRIBUNAIS PARA DEPENDENTES QUIMICOS. Definindo os Tribunais para Dependentes Químicos: os Componentes Chave. Washington, D.C., Escritório de Programas de Justiça, Departamento de Justiça, 1997.

EWALD, F. Foucault, a Norma e o Direito. Lisboa: Vega, 2000.

FOUCALT, M. Sobre a Prisão. In: Microfísica do Poder. Rio de Janeiro: Edições Graal, 1979.

Vozes, 1991.

Vigiar e Punir: Nascimento da Prisão. Petrópolis: Editora, 1996.
Em Defesa da Sociedade: Curso no Collège de France (1975-1976). São Paulo: Martins Fontes, 1999.

Inquirição sobre as Prisões: Quebremos a Barreira do Silêncio (1971a). In: Ditos e Escritos IV. Estratégia, Poder-Saber. Rio de Janeiro: Forense Universitária, 2003.

. Manifesto do GIP. Ditos e Escritos IV (1971b)

IV (1975a).

. A Prisão Vista por um Filósofo Francês. Ditos e Escritos

Prefácio. In: Jackson. Ditos e Escritos IV (1975 b). HUCO V O Último Dia de um Condenado à Morte. Rio de Janeiro: Newton Compton Brasil Ltda., 1995.

KARAM, M. L. Drogas: a Irracionalidade da Criminalização. In: Bentes, L. \& Gomes, R. F. (orgs). O Brilho da Infelicidade. Rio de Janeiro: ContraCapa Livraria, 1998.

Aspectos Jurídicos. In: Seibel, S. D. \& Toscano Junior, A. (orgs). Dependência de Drogas. São Paulo: Atheneu, 2001.

MAIEROVITCH, W. F. O Efeito da Droga. BISA - Boletim Informativo sobre Aids e Drogas), Belo Horizonte, 23, p. 5, ago./set. 2002.

MILLER, J.- A. A Máquina Panóptica de Jeremy Bentham. In: Silva, T. T. da (org.). O Panóptico. Jeremy Bentham. Belo Horizonte: Autêntica, 2000.

NATIONAL DRUG COURT INSTITUTE. Desenvolvimento e Implementação de Sistemas de Tribunais para Dependentes Químicos. Washington, D.C., Escritório de Programas de Justiça, Departamento de Justiça, maio de 1999.

SOUZA, M. DE. A Sociedade Disciplinar, a Opinião Pública e o Jornal. In: Cadernos de Subjetividade/Núcleo de Estudos e Pesquisas da Subjetividade do Programa de Estudos Pós-Graduados em Psicologia Clínica da PUC-SP-v.1, n.1, São Paulo, 1993.

WACQUANT, L. Punir os Pobres: a Nova Gestão da Miséria nos Estados Unidos. Rio de Janeiro: Instituto Carioca de CriminologiaFreitas Bastos, 2001
Referências 